\title{
O Brasil sob o impacto dos novos desafios conceituais e práticos das Operações de Paz
}

\section{Brazil and the new conceptual and pratical challenges of Peace Operacions}

Rev. Bra. Est. Def. v. 3, nº 2, jul./dez. 2016, p. 17-22

ISSN 2358-3932

\section{MONICA HIRST}

Muito obrigada, Antonio Jorge, pela sua generosa apresentação, e agradeço também ao ENABED pelo convite para integrar estar mesa. Esta é a primeira vez que eu participo de um encontro da ABED e tenho achado muito interessante não só a programação, mas a possibilidade de também rever colegas e me atualizar sobre a produção de conhecimento na área de estudos da defesa. Num momento político tão difícil como o que estamos atravessando no país a dimensão de segurança e defesa corresponde a uma dimensão essencial da agenda doméstica.

O que eu vou tentar nesses 20 minutos - considerando inclusive que eu sou a primeira a expor - é trilhar um caminho do global ao nacional, passando pelo regional, abordando o que hoje creio ser necessário pensar criticamente, quando nós falamos de missões de paz, da participação em operações de paz e da articulação regional. Esta problemática ganhou, como sabemos, uma nova visibilidade e importância, não somente na Pós-Guerra Fria, mas na Pós-pós-Guerra Fria. A questão da intervenção internacional passou à ordem do dia, do ponto de vista das opções da alta política internacional, na qual as decisões e os mandatos definidos e configurados no Conselho de Segurança das Nações Unidas constitui uma parte central dessa agenda. Neste contexto, as operações de paz, que sequer estavam na carta original das Nações Unidas, são agora parte ativa de um cotidiano de intervenção e articulação multilateral em contextos de crises severas, desastres naturais e conflitos internos.

Nos anos recentes essa importância e essa visibilidade estiveram vinculadas a um quadro de mudanças. A agenda das operações de paz vem sofrendo não só modificações em função dos cenários em que elas ocorrem, mas - e é isso que eu gostaria de sublinhar - em função das discussões

Monica Hirst - Professora titular da Universidade Nacional de Quilmes e docente no Mestrado de Estudos Internacional da Universidade Torcuato di Tella-Argentina. E-mail: jbattaglino@utdt.edu. 
normativas, metodológicas, procedurais que ocorrem dentro das Nações Unidas para estabelecer um receituário - o que se chama de regras de engajamento - a ser observado. Naturalmente, essas prescrições foram mudando, principalmente a partir do Relatório Brahimi que, em 2000, tentou formular uma receita normativa para as missões de paz. Neste ano, o Alto Painel das Nações Unidas revisitou o relatório e redefiniu algumas prioridades e propôs novos enfoques. Eu destacaria cinco prioridades: primeiro, a de que as operações de paz devem se dar a partir de um acordo abrangente entre os atores nas áreas de segurança, desenvolvimento e política; a segunda se refere à necessidade de que os acordos políticos buscados devem ser inclusivos, ou seja, envolvendo as diferentes partes em conflito; a terceira diz respeito ao apoio financeiro aos processos de construção da paz; em quarto lugar destaca-se a importância - e vou voltar a isso - dos atores regionais e dos países vizinhos no seu envolvimento no processo de pacificação; e em quinto lugar sublinha-se questão de gênero, tendo em vista a participação crucial da mulher nos processos de paz, tanto do ponto de vista do cenário doméstico como dos atores da intervenção.

A este mapeamento devemos somar as modificações institucionais recentes dentro das Nações Unidas; o desenho de uma nova arquitetura burocrática, a criação da Comissão da Construção da Paz, a importância dos fundos da paz e o emaranhado de diferentes segmentos da organização envolvidos com essa agenda.

O que me interessa aqui é vincular estas modificações com o que eu chamaria "o tabuleiro das controvérsias em relação às operações de paz”. E, nesse caso, as discussões que ocorrem dentro do Conselho de Segurança, em torno de missões específicas ou em torno à problemática das operações de paz - um tema revisitado todos os anos pelo Conselho - permitem observar uma clara divisão Norte-Sul. Esta divisão não é suscitada pelos mesmos atores, até porque uma parte importante da contribuição do Sul nessa discussão é nutrida por membros não permanentes do Conselho de Segurança, que devem obedecer a regra do revezamento regional. Percebemos claramente uma continuidade de posições, mais ou menos alinhadas, do Sul diante de certas problemáticas. Vou rapidamente mencioná-las. Uma é a da caracterização do que são hoje em dia as ações robustas e quais as suas periculosidades. Essas ações abrem um espaço para o que alguns já rotulam como capitulo 7 1/2 da carta das Nações Unidas, em função da utilização de novos métodos e procedimentos no terreno. Existem cenários específicos que colocam à prova esses novos métodos. Eu não vou entrar aqui no território do Congo, que pertence ao meu colega de mesa (o Gal. Santo Cruz), mas menciono, de qualquer maneira, a introdução das brigadas de intervenção, a utilização sistemática de drones, 
ou seja, tudo que foi incorporado no bojo das operações robustas. Outro procedimento em discussão é o da cooperação entre as missões. A ideia de que, a qualquer momento, possa ser solicitada a colaboração de uma missão que está mais ou menos na mesma área. O que se discute é o risco da improvisação que esse tipo de procedimento gera. No Sudão, isso foi experimentado e gerou uma série de controvérsias. Um terceiro ponto, muito discutido no Conselho, é o da divisão de trabalho entre os que pagam e os que fazem; a ideia de que decide quem paga, e não quem faz. Esta questão remete à subutilização dos mecanismos de consulta que existem no Conselho de Segurança, aos contribuintes de forças e ao reclamo de que a Assembleia Geral disponha de mais voz, o que por sua vez remete à necessidade de seja repensado o $5^{\circ}$ comitê da própria Assembleia. Enfim, uma série de discussões aparecem vinculadas à ideia de que o Sul comparece com a mão de obra, mas não conta com as prerrogativas para atuar nas discussões financeiras, é marginalizado nas discussões sobre os conteúdos das missões de paz.

Outro tema debatido diz respeito ao conceito de multidimensionalidade das missões de paz. Este foi um conceito introduzido já há mais de dez anos para configurar as operações de paz. Mas justamente ele foi elaborado ainda muito sob a influência do Informe Brahimi - quando a inclusão do capítulo do desenvolvimento e do compromisso com o desenvolvimento se definiram como parte das tarefas das operações de paz. E, justamente, o que está se discutindo atualmente é que, cada vez mais, se utiliza o conceito da multidimensionalidade sem ajustar os orçamentos das operações. Este descompasso acaba criando um déficit e uma frustração, já que um conjunto de compromissos estabelecidos pelos mandatos do Conselho de Segurança não podem ser cumpridos.

Finalmente, destaco o ponto da importância dos atores regionais e de como nossa região e o Brasil, em particular, se posicionam diante desta questão. Tornou-se sistemática a valorização no Conselho de Segurança a valorização dos atores regionais e, principalmente, das organizações regionais. Estas assumem compromissos não somente de envio de contingentes, mas também de responsabilidades políticas nas Operações de Paz. O que se discute neste caso é que essa tendência representa um processo de sinergização do capítulo 7 com o capítulo 8 da carta da ONU. O capítulo 8 da carta valoriza as organizações regionais como uma instância para solucionar conflitos. Não obstante ele agora aparece crescentemente subordinado ao capítulo 7, que, por sua vez, vem sendo reinterpretado, para legitimar a imposição da força nos mandatos das Nações Unidas. Cria-se aqui um desvio das expectativas originais que se tinham das organizações regionais. No caso da África, isso é claríssimo com a União Africana. Soma-se ainda 
uma discussão sobre a União Africana: enquanto que, em alguns casos, ela é valorizada; em outros - como foi o caso da intervenção na Líbia em 2011 - ela é praticamente colocada para escanteio. O que se queria era intervir na Líbia e não buscar uma solução regional.

Como a nossa região se inclui nessa discussão? Nós temos mostrado uma enorme reticência de colocar as nossas organizações regionais antigas e novas a serviço dessa agenda. Ou seja, a atuação em Operações de Paz se dá multilateralmente nos espaços da governança global. Nós utilizamos - como mostrou o caso do Haiti - o guarda-chuva das Nações Unidas mesmo quando queremos desenvolver uma ação com um selo regional, como foi a Minustah (Missão das Nações Unidas para Estabilização do Haiti). Existem razões para este comportamento, mas também existem custos políticos e estratégicos que a região começa a sofrer em função desse tipo de decisão. O processo de pacificação na Colômbia, que é, neste momento, como foi dito ontem neste encontro, de enorme relevância, mostra claramente como nós, como região, optamos por uma atuação fragmentada e claramente marginal nesse processo. Isso ocorre também no processo que começa agora de construção e estabilização da paz na Colômbia. Temos a tendência de atuar à margem, mas a questão de atuar à margem - e a Minustah, a partir de 2010, mostra isso claramente - conduz à tendência de fragmentação que impede uma ação coordenada da região.

A atuação do Brasil nesse cenário nos anos recentes - não preciso me aprofundar - é expansiva. Ela se dá com novas responsabilidades, de atuações em nomes do governo ou em nome de uma expertise. Nossa presença, que se expandiu na burocracia das Nações Unidas e em missões específicas - a atuação do Santos Cruz é um belo exemplo nesse sentido, permite que aprofundemos a tendência de uma articulação com a governança global. Mas esta mesma presença ocorre em detrimento de um trabalho sistemático de vinculação com a dimensão regional.

Termino com uma reflexão sobre a nossa presença no Haiti. Trata-se de uma presença que hoje em dia implica custos políticos muito altos, tendo em vista a situação política local e a dificuldade que a Minustah vem tendo para criar uma agenda positiva junto à população haitiana. Mas o que é também preocupante é que nós entramos no Haiti em 2004 em defesa de um projeto regional de intervenção. E, claramente, hoje em dia a nossa atuação está dissociada deste objetivo. Uma indicação neste sentido se deu no ano passado quando a Argentina decidiu individualmente retirar-se quase por completo do Haiti. Acho até que o governo Kirchner fez um favor para o governo Macri, retirou os batalhões argentinos do Haiti, antes que a situação do Haiti deteriorasse ao ponto que deteriorou nesse momento, o que dá ao governo Macri muito mais liberdade de atuação. Mas esta deci- 
são não foi articulada regionalmente; ela foi fruto de uma visão crítica aos novos procedimentos que eu mencionei anteriormente. Nossa presença no Haiti já não tem a marca regional que teve no início da Minustah. Eu faço, inclusive, enfim, uma comparação que é bastante infeliz, mas nem por isso pouco ilustrativa. Comparo nossa atual desarticulação regional no Haiti com o que nos ocorreu na Guerra do Paraguai. Entramos como resultado de uma tríplice aliança, articulada com a Argentina e com o Uruguai, e ao final cada país assinou a paz em separado. A dificuldade que nós temos de trabalhar de forma sistemática e articulada em termos regionais é, a meu juízo, dramática. Tenho a esperança que a presença do Antônio Jorge na Unasul venha ajudar a superar essa dificuldade.

Muito obrigada. 


\section{RESUMO}

Apresentação da Professora Monica Hirst, na mesa redonda "A Participação Brasileira em Operações de Paz e seus Reflexos para as Relações Civis-Militares no País” durante o IX Encontro Nacional da ABED.

Palavras-chave: Operações de Paz; Brasil; MINUSTAH.

\section{ABSTRACT}

Professor Monica Hirst's presentation at the roundtable entitled "The Brazilian participation in Peace Operations and its effects on civilian-military relations"(IX ABED National Meeting).

Keywords: Peace Operations; Brazil; MINUSTAH. 